\title{
TRANSITION FLIGHT EXPERIMENTS ON A SWEPT WING WITH SUCTION
}

\author{
D. V. Maddalon* \\ F. S. Collier, Jr. ${ }^{+}$ \\ L. C. Montoya ${ }^{\dagger}$ \\ R. J. Putnam ${ }^{\ddagger}$ \\ Presented at the IUTAM Third Symposium on \\ Laminar-Turbulent Transition \\ Toulouse, France \\ September 11-15, 1989 \\ * NASA, Langley Research Center, Hampton, VA \\ + High Technology Corp., Hampton, VA \\ $\dagger$ NASA, Dryden Flight Research Center, Edwards, CA
}

$\ddagger$ PRC Kentron, Hampton, VA 


\title{
TRANSITION FLIGHT EXPERIMENTS ON A SWEPT WING WITH SUCTION
}

D. V. Maddalon

NASA Langley Research Center, Hampton, Va. USA

F. S. Collier, Jr.

High Technology Corporation, Hampton, Va. USA

L. C. Montoya

NASA Dryden Flight Research Facility, Edwards AFB, USA

R. J. Putnam

PRC Kentron, Hampton, Va. USA

\begin{abstract}
Flight boundary-layer transition experiments were conducted on a 30 degree swept wing with a perforated leading-edge suction panel. The transition location on the panel was changed by systematically varying the location and amount of suction. Transition from laminar to turbulent flow was due to leading-edge turbulence contamination or crossflow disturbance growth and/or Tollmien-Schlichting disturbance growth- depending on flight condition and suction variation. Amplification factor correlations with transition location were made for various suction configurations using a state-of-the-art linear stability theory which accounts for body and streamline curvature and compressibility.
\end{abstract}

$\begin{array}{ll}\text { Nomenclature } \\ C_{p}, C P & \text { Pressure coefficient } \\ C_{q}, C Q & \text { Suction coefficient } \\ K & \text { Non-dimensional suction velocity } \\ \text { LE } & \text { Leading Edge } \\ M & \text { Freestream Mach number } \\ N & \text { Amplification factor, where } N=\ln \left(A / A_{0}\right) \\ r & \text { Leading-edge radius (normal) } \\ R / f t, R / F T & \text { Freestream unit Reynolds number } \\ R_{\theta} & \text { Reynolds number based on momentum thickness } \\ & \text { of the attachment-line boundary layer } \\ S / C & \text { Distance measured along surface, streamwise } \\ t / c & \text { Thickness ratio (normal) } \\ X / C & \text { Distance measured along chord, streamwise } \\ \text { Greek } & \\ \delta_{0.995} & \text { boundary-layer thickness where } U / U_{e}=0.995 \\ \theta & \text { momentum thickness } \\ \mu & \text { laminar coefficient of viscosity } \\ \lambda & \text { sweep angle in degrees, or wavelength } \\ \text { Subscripts } & \\ a . l . & \text { at the attachment line } \\ C F & \text { crossflow } \\ e & \text { boundary-layer edge } \\ m a x & \text { maximum } \\ T S & \text { Tollmien-Schlichting } \\ T & \text { at transition }\end{array}$




\section{Introduction}

The achievement of laminar flow on swept wings at the Reynolds numbers and sweep angles typical of modern, high subsonic-speed, commercial transports is a formidable task. For leading-edge sweep angles above approximately 15 degrees, transition may occur very near the leading edge due to the uncontrolled growth of crossflow disturbances in the laminar boundary layer. In addition, attachment-line contamination from the turbulent fuselage can dash the possibility of achieving any laminar flow on the wing. Leading-edge suction is an effective method of controlling the growth of these disturbances. Combined with a 'tailored' pressure gradient over the wing box to control Tollmien-Schlichting (TS) disturbance growth, this configuration (hybrid laminar-flow control, HLFC) may result in extensive amounts of laminar flow on future transport aircraft wings.

Recently, the NASA completed the Leading Edge Flight Test (LEFT) Program as a flight validation of laminar flow control leading-edge systems. During this program, a complete perforated LFC leading-edge suction panel (and associated systems) was installed and tested in the right wing of a JetStar aircraft to gain operational experience from which the concept's practicality could be assessed. (See figure 1.) References 1 through 3 provide a description of this program. At the end of the LEFT program, this aircraft performed a series of transition research experiments, the first of which is described in this paper. These experiments assessed the sensitivity of transition location on the leading-edge suction panel to suction variations.

\section{Experimental Apparatus}

A schematic of the LFC test article is presented in figure 2. The outer face of the suction surface panel was a 0.025 inch thick titanium sheet perforated with over 1 million holes of 0.0025 inch diameter (drilled by an electron beam) spaced about 0.035 inch between centers. The panel core and inner face sheet were fiberglass. Flutes were used for the subsurface suction air collection. Bond areas between the perforated surface and the flute core were impervious to flow. Thus, suction on the surface was along fifteen spanwise perforated strips of about 0.62 inch chord separated by non-suction strips of about 0.38 inch chord. Flute air flow was individually controlled from the aircraft cabin with adjustable sonic needle valves. Suction could be applied to the upper surface from just below the leading-edge highlight to the front spar joint $(\mathrm{X} / \mathrm{C}=13$ percent $)$. A description of the perforated leading edge was provided in reference 1 . No attempt was made to achieve laminar flow beyond the front spar.

The perforated leading edge housed a Krueger-type device that deployed to provide the test surface with line-of-sight protection against insect impacts during takeoff and landing. The modification to the wing spanned about 7 feet with the suction article about 5 feet in span. The test article was swept 30 degrees, the normal chord was about 9.8 feet and the normal nose radius about 1.69 inches. 
To produce the desired pressure distribution, the wing section required extensive modification. Wing contour (to the rear spar on the upper surface and to the front spar on the lower surface) was changed with the installation of the test article and fiberglass fairings over the wing box and at the test article edges.

\section{Instrumentation}

Near surface Pitots were used to determine if laminar flow existed at the front spar, and to locate the approximate transition location ahead of each Pitot. A description of the procedure was given in reference 2. The Pitots were calibrated in flight to determine transition location by placing three-dimensional roughness transition strips at known locations on the test surface. Boundary layer state (laminar or turbulent) was measured about every three inches over a five foot span at the front spar. The location of all instrumentation used on the test article is given in figure 2.

\section{Experiment Description}

Experiments were conducted at test conditions which included nominal Mach numbers of $0.70,0.75$, and 0.775 and altitudes of $29000,31000,33000,35000$ and 37000 feet. For simplicity, combinations of flight conditions are referred to with the Mach number stated first and then the altitude; that is, 0.775 Mach and 29000 feet is denoted as $0.775 / 29000$. Figure 3 provides the measured chordwise pressure distribution at the $0.775 / 29000$ test condition selected for analysis. At this test condition, the test-article chordwise pressure gradient was nearly flat beyond $X / C=0.05$. Research parameters included variations of the location and amount of suction. Suction was varied chordwise by progressively sealing spanwise perforated strips from either the front or rear direction.

\section{Spanwise Turbulence Contamination}

The problem of spanwise turbulence contamination along the attachment-line of a swept wing has been studied in Refs. 4-6. Pfenninger (ref. 4) suggests using the attachment-line momentum thickness Reynolds number defined as:

$$
R_{\theta}=\sin \lambda[.1425 K+.405][(r \times R / f t) /(\cos \lambda \times(1+t / c))]^{1 / 2}
$$

to correlate transition of the attachment-line boundary layer with suction in the presence of large disturbances. The amount of suction used in the present experiment reduced the momentum thickness Reynolds number at the attachment line about 7 percent compared to no suction. It was observed that for some flight conditions there was more laminar flow outboard than inboard. This was due to the smaller outboard nose radius and the resulting larger leading-edge velocity gradient, each of which lowers the momentum thickness Reynolds number. Figure 4 summarizes the experimental attachment-line momentum thickness Reynolds number with suction at a wide variety of flight conditions using eq. (1). For $R_{\theta}$ greater than about 94 , leading-edge turbulence contamination 
causes transition. These data show remarkable agreement with the results of reference 4.

Reference 3 described the spanwise turbulence contamination encountered during initial flight testing and its alleviation by use of a 'Gaster bump' (ref. 5) and leading-edge notch combination. The following observations were made for the present experiment. Without the bump and without suction on the attachment line, very little laminar flow was obtained. Without the bump, but with suction on the attachment line, laminar flow is obtained over most of the span of the test section except for the most inboard location. With the bump, laminar flow was obtained with or without suction on the attachment line for $R_{\theta}$ significantly higher than 94 .

\section{Suction Location}

Suction location is known to influence laminar boundary-layer flow. Early suction can be used to damp crossflow disturbance growth before it amplifies and causes transition. Theoretical investigations of both two dimensional and axisymmetric flows (refs. 7-8) have shown that suction requirements for laminar flow can be minimized by the application of suction early where disturbances are small rather than the application of suction farther downstream where the disturbances are highly amplified. Wind tunnel experiments (refs. 9-10) have confirmed the two-dimensional theoretical results. There are, however, no flight data on actual wing surfaces where measurements are concentrated in the leading edge. The present test article was used to make these measurements. Questions studied include the effect of suction in the leading-edge region where crossflow was dominant and also the effect of suction closer to the front spar where the relatively flat pressure gradient tends to damp crossflow but promote Tollmien-Schlichting disturbance growth.

Typical suction distributions are given in figure 5. Nominal suction levels (fig. 5-6) were representative of that required in the leading edge of an LFC wing designed for nearly full chord laminar flow; that is, more suction than required for laminar flow to the front spar. Nominal suction requirements were defined in this way in the test-article design so that suction ducting volume would represent future transport applications with extensive laminar flow. High initial suction levels were required to control crossflow at the leading edge. Beyond $\mathrm{S} / \mathrm{C}=0.05$, a lower level of $C_{q}$ was maintained to the front spar. The possibility exists, however, that disturbances from the high suction flow through the perforations (ref. 11) may grow downstream of the front spar and move transition forward at large length Reynolds numbers.

For comparison purposes, the measured suction coefficient averaged over the entire

perforated area is inset in the $C_{q}$ figures. The seven numbers included in the legend next to the test article planform specify, respectively, flight number, time of day, Mach number, altitude, unit Reynolds number per foot, charge patch reading in microamperes (an indication of ice particles, see ref. 2), and average transition location (\% chord). 
When the average transition location is given as 13.0 , the test article was entirely laminar. In referring to these figures, a shortened notation is used (planform 2 of figure 5 is referred to as figure 5-2).

The effect of suction location was measured by sealing flutes spanwise at either the trailing edge or leading edge of the test article. Suction was progressively added from either the rear (later suction, fig.5) or forward direction (early suction, fig. 6). These data clearly show the importance of suction location in controlling crossflow; transition occurs near the leading edge when suction is applied only to flutes 6-15 (fig. 5-2) or flutes 5-15 (fig. 5-3). With suction at flutes 4-15 (fig. 5-4), laminar flow was suddenly obtained to the front spar! Adding suction from the front direction (fig. 6) shows that laminar flow was not generally obtained to the front spar until suction was used on flutes 1-6 (fig. 6-4). The localized loss of laminar flow, probably due to the slight adverse gradient near the front spar caused by the Pitot rake installation, was eliminated with further suction through flute 15 (fig. 6-6).

Data are also compared where suction was applied to flutes 1-5 (fig. 6-3) vs 5-15 (fig.5-3); overall suction up to the transition point was maintained at about the same level and early suction yields a longer run of laminar flow $\left[(X / C)_{T}=0.095\right.$ for early suction and 0.065 for later suction]. The darkened area in suction coefficient figure 5-3 represents suction used past the average transition point.

\section{Comparison With Theory}

Boundary layer stability calculations were made using a state-of-the-art linear stability theory which accounts for streamline and surface curvature and compressibility (ref. 12) to determine the effect of suction location and magnitude on disturbance growth as indicated by the $\mathrm{N}$-factor. For nominal suction (fig. 5-6), $\mathrm{N}$-factors computed with and without curvature are presented in figure 7 for $6000 \mathrm{~Hz}$. and $0 \mathrm{~Hz}$. (for the pressure distribution shown in fig. 3). A range of frequencies were computed to determine the frequency which produced the largest $\mathrm{N}$-factor at the transition location or at the front spar, and disturbances near $6000 \mathrm{~Hz}$. were found to be most amplified (fig. 7). The N-factor computed without curvature at $6000 \mathrm{~Hz}$. reaches the currently assumed critical value for transition of 9 (based on previous correlations) at about 3 percent chord (fig. 7) although the boundary layer was laminar to at least 13 percent chord. When curvature was accounted for, the $\mathrm{N}$-factor for the most amplified frequency was well below this assumed critical value and the boundary layer was stable from about 5 percent chord to the front spar (fig. 7). This result emphasizes the importance of including the dominant physical effects (body and streamline curvature, compressibility, etc.) in the stability calculations.

A comparison of the $\mathrm{N}$-factors (including curvature) for the no suction and nominal suction cases is presented in figure 8 . With no suction, transition occurs at $X / C=0.021$ which was an average value determined from the experimental measurements (figure 5- 
1). The wave orientation angle, $\psi$, and wavelength to boundary-layer thickness ratio, $\lambda / \delta$, of the most amplified disturbance at transition were computed as about 84 degrees and 4.3, respectively. These are values typical of crossflow disturbances, indicating that transition was due to crossflow disturbance growth. The $\mathrm{N}$-factor at transition was about 8.4 for no suction at the most amplified frequency. In figure 8 , the effect of suction reduces the amplification rates (and hence the $\mathrm{N}$-factor) of the crossflow vortices well below the critical value, and laminar flow was achieved to the front spar (as indicated by the experimental measurements shown in figure 5-6).

The effect of suction location and magnitude on the stability of the boundary layer is presented in figures 9 and 10. In figure $9, \mathrm{~N}$-factor calculations as a function of $X / C$ are shown for the cases of no suction and suction on flutes 8-15, 7-15, 6-15, 5-15, and 4-15 (later suction) at $6000 \mathrm{~Hz}$. which was (or very close to) the most amplified frequency for each suction configuration. (See figure 5 for experimentally determined transition locations.) In each case the growth of crossflow disturbances in the laminar boundary layer was significant, causing transition ahead of the front spar in all cases except for the case of suction on flutes 4-15. The N-factor at transition for the other suction configurations was between about 10.0 and 10.5 for travelling disturbances. For stationary crossflow disturbances $(\mathrm{F}=0 \mathrm{~Hz}$.), the $\mathrm{N}$-factor at transition was about 5.5. (See Table 1.) The maximum $\mathrm{N}$-factor for the case of suction on flutes 4-15 does not exceed 8.5 and, as mentioned, the experiment shows laminar flow to the front spar. For suction on flutes 8-15, suction does not influence transition since all the suction was aft of the transition location.

In figure 10, the $\mathrm{N}$-factor calculations for the cases referred to as early suction are presented along with the no suction case. With suction applied to flutes 1 and 2, transition was experimentally determined to occur at $X / C=0.035$ (fig. 6-2), and according to stability theory, transition was dominated by the growth of crossflow disturbances with wave orientation about 84 degrees at transition. The $\mathrm{N}$-factor at transition was about 7.6. As more suction was added, transition moved farther back along the chord. With suction on flutes 1-5, 1-6, and 1-7, the stability theory predicts that crossflow-like disturbances are most amplified to about 4 percent chord followed by a region where TS waves are most amplified (fig. 10). For suction on flutes 1-5, the wave orientation angle was 45.5 degrees, the wavelength to boundary-layer thickness ratio was 12.5 (values typical of TS waves) and the $\mathrm{N}$-factor is about 7.8 at the transition location of 9.5 percent chord. In general, the $\mathrm{N}$-factors at transition for early suction are somewhat lower (about 8) than those associated with later suction (about 10, see Table 1 for a comparison); although no definite conclusions can be drawn at this point, possible explanations include an equivalent roughness effect due to the flow into the suction holes, uncertainity in the exact location of transition onset, and the fact that few $\mathrm{N}$-factor correlations with transition location exist for flows where both crossflow and TS are 
highly amplified.

The crossflow Reynolds number at transition (previously used as an indicator of transition, ref. 6) as a function of leading-edge sweep angle is presented in figure 11 for a number of earlier investigations. The present data (taken where transition occurred in a favorable chordwise pressure gradient) agrees very well with reference 6 which determined the critical value of crossflow Reynolds number to be about 325 .

\section{Summary}

Laminar flow research with suction on the leading edge of a 30-degree swept wing was accomplished. Achievement of laminar flow on the entire test article required both a bump on the inboard leading edge to control attachment-line contamination, and suction on the test article to control crossflow and TS disturbance growth. Laminar flow was obtained over the test article to the front spar with nominal suction. Early suction on the leading edge yielded more laminar flow than did later suction for the same amount of overall suction. A state-of-the-art linear stability theory which accounts for body and streamline curvature and compressibility showed that the curvature effects reduced local disturbance amplification by as much as 60 percent for the configuration studied. $\mathrm{N}$-factors at transition varied from about 7.5 to 10.5 .

\section{References}

1. Douglas Aircraft Company Staff: Laminar Flow Control Leading Edge Flight Test Article Development. NASA CR-172137, 1984.

2. Davis, R.E.; Maddalon, D.V.; Wagner, R.D.; Fisher, D. F.; and Young, R.: Performance of Laminar Flow Leading Edge Test Articles and Cloud Detection Instruments During the NASA Left Program. NASA TP 2888, 1989.

3. Wagner, R.D.; Maddalon, D.V.; and Fisher, D.F.: Laminar Flow Control Leading Edge Systems in Simulated Airline Service. ICAS-88-3.7.4, Jerusalem, Israel. 1988.

4. Pfenninger, W.: Laminar Flow Control Laminarization. AGARD-R-654, June 1977.

5. Gaster, M.: A Simple Device for Preventing Turbulent Contamination on Swept Leading Edges. Journal of the Royal Aeronautical Society, Vol. 69, pg. 788, 1965.

6. Poll, D. I. A.: Some Aspects of the Flow Near a Swept Attachment Line With a Particular Reference to Boundary Layer Transition. Cranfield Institute of Technology, CoA Report No. 7805, 1978.

7. Reed, H.L.; and Nayfeh, A.H.: Numerical Pertubation Techniques for Stability of Flat Plate Boundary Layers with Suction. AIAA Journal, Vol. 24, No. 2, pp. 208-214, 1986.

8. Nayfeh, A.H.; and Reed, H.L.: Stability of Flow over Axisymmetric Bodies with Porous Suction Strips. Physics of Fluids, Vol. 28, No. 10, pp. 2290-2998, October 1985.

9. Reynolds, G. A.; and Saric, W.S.: Experiments on the Stability of the Flat Plate Boundary Layer with Suction. AIAA Journal, Vol. 24, No. 2, pp. 202-207, 1986.

10. Saric, W.S., and Reed, H.L.: Effect of Suction and Weak Mass Injection on Boundary Layer Transition. AIAA Journal, Vol. 24, No. 3, pp. 383-389,1986.

11. Goldsmith, J.: Critical Laminar Suction Parameters for Suction Into an Isolated Hole or a Single Row of Holes. Report No. BLC-95, February, 1957.

12. Collier, F.S., Jr.: Curvature Effects on the Stability of Three-Dimensional Laminar Boundary Layers. Ph.D. Dissertation, Virginia Polytechnic Institute and State University, May 1988. 
Table 1: Summary of $\mathrm{N}$-factor correlations with transition locations at $\mathbf{0 . 7 7 5} / 29000$.

\begin{tabular}{lllllll}
\hline Suction & $(X / C)_{T}$ & $N_{\max }$ & $N_{\max }(0 \mathrm{~Hz})$. & $\left(R_{C F}\right)_{T}$ & $\psi(\mathrm{deg})$. & $\lambda / \delta_{0.995}$ \\
\hline & & & & & & \\
None & 2.1 & 8.4 & 5.1 & 317 & 83.9 & 4.3 \\
$8-15$ on & 3.9 & 10.6 & 5.7 & 350 & 82.2 & 4.6 \\
$7-15$ on & 3.9 & 10.4 & 5.7 & 350 & 82.9 & 4.5 \\
$6-15$ on & 4.2 & 10.0 & 5.6 & na & 83.2 & 4.4 \\
$5-15$ on & 6.5 & 9.9 & 5.4 & na & 82.4 & 4.6 \\
$1-2$ on & 3.5 & 7.6 & 5.1 & 340 & 82.3 & 4.6 \\
$1-5$ on & 9.5 & 7.8 & stable & na & 45.5 & 12.5 \\
$1-6$ on & 12.4 & 8.4 & stable & na & 54.8 & 12.6 \\
\hline
\end{tabular}

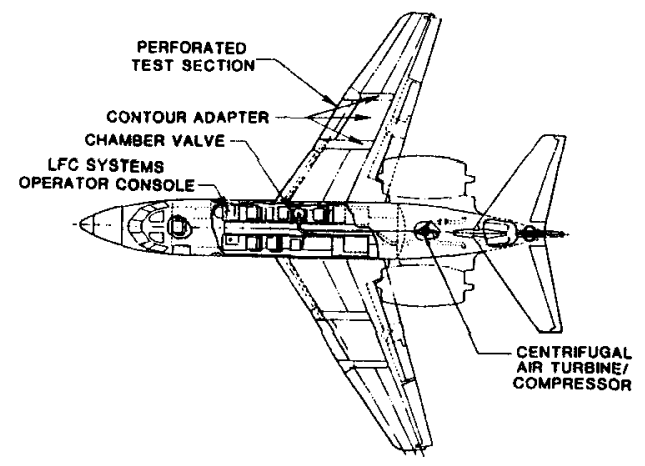

Figure 1. Suction leading-edge test aircraft.

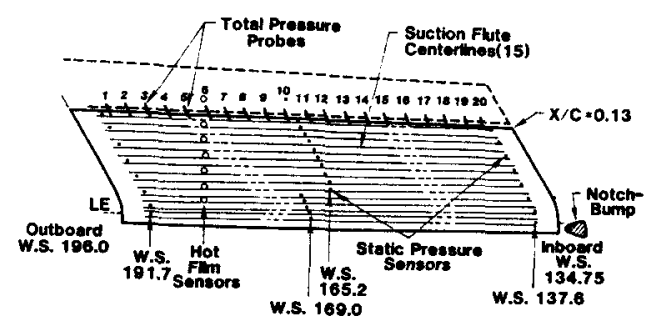

Figure 2. Perforated test article surface instrumentation.

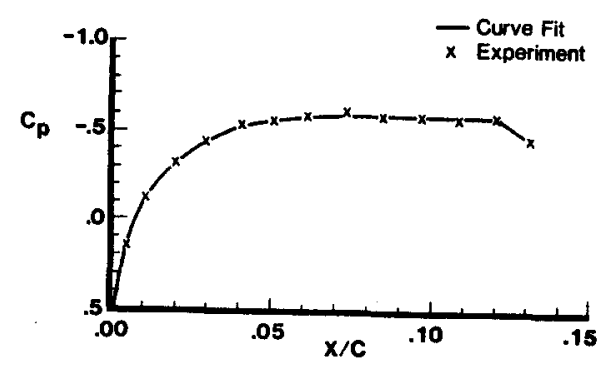

Figure 3. Pressure coefficient distribution at $M=0.775$ and $29000 \mathrm{ft}$.

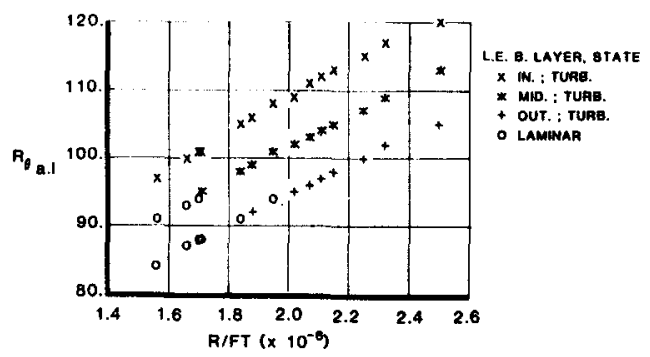

Figure 4. Experimental attachment line momentum thickness Reynolds number without bump; Sweep=30 deg., $M=0.700$ to $0.775,25000$ to $37000 \mathrm{ft}$. 


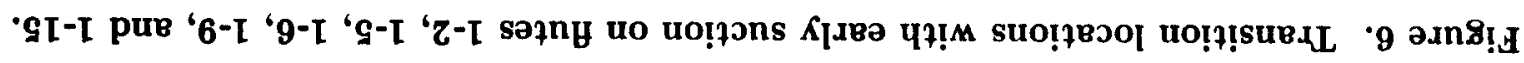

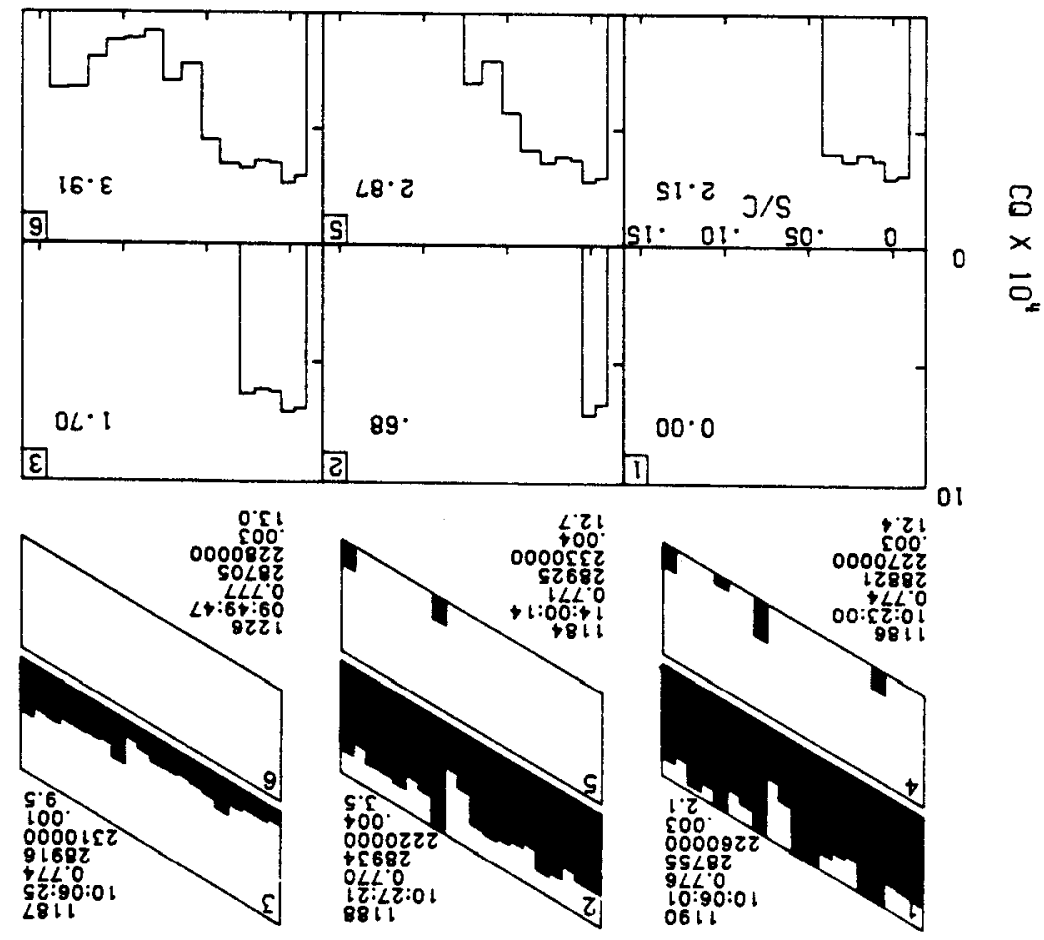

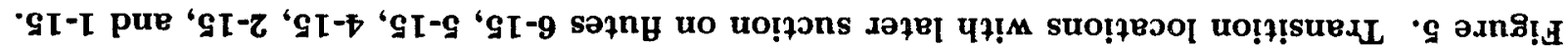

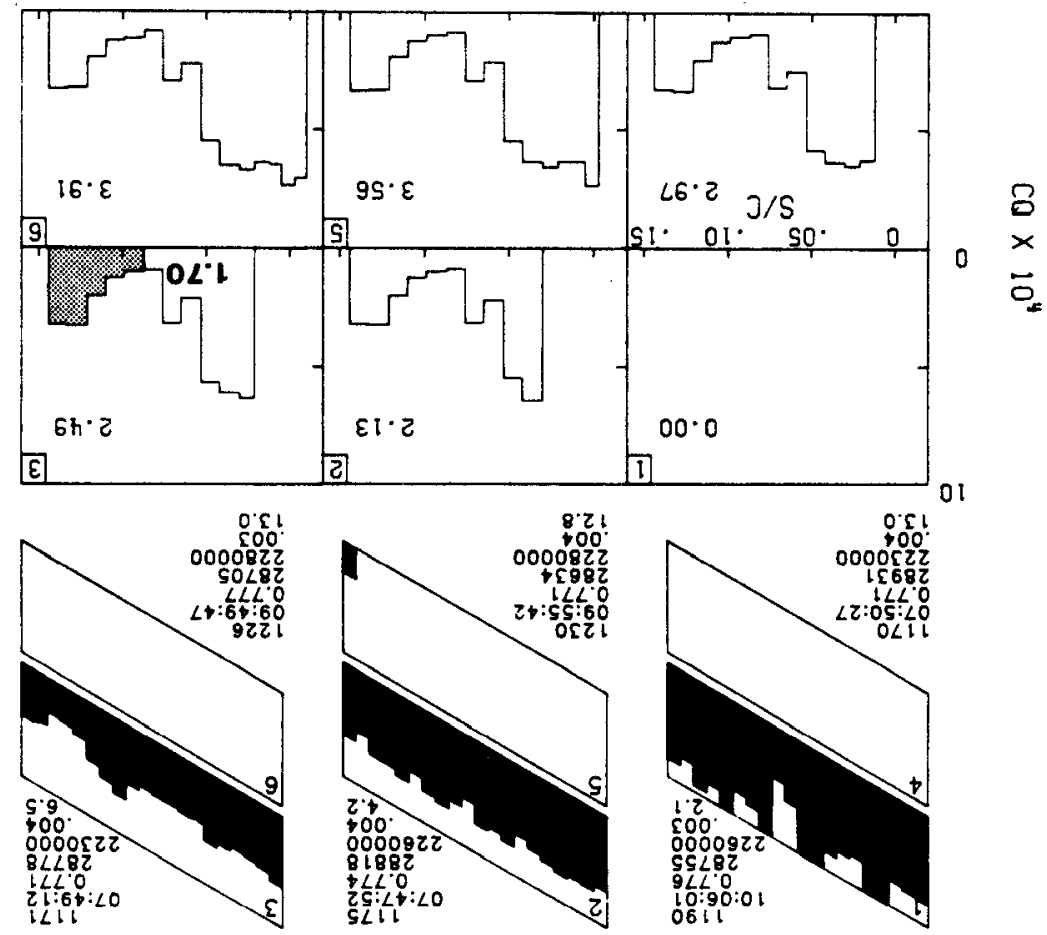




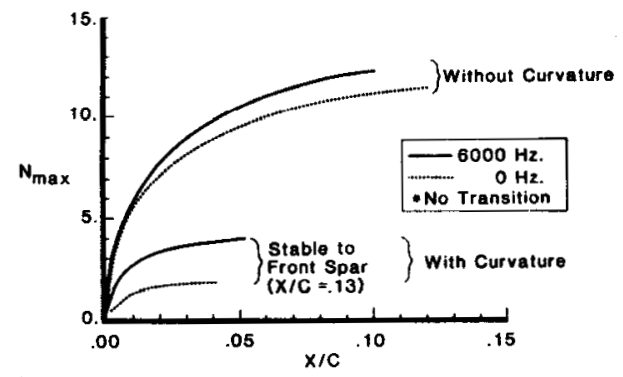

Figure 7. Effect of curvature on laminar boundary layer stability at $M=0.775$, $29000 \mathrm{ft}$. and nominal suction.

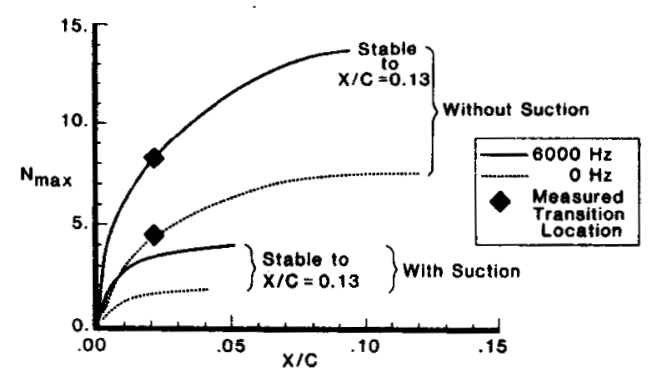

Figure 8. Effect of suction on laminar boundary layer stability at $M=0.775,29000$ ft. including curvature effects.

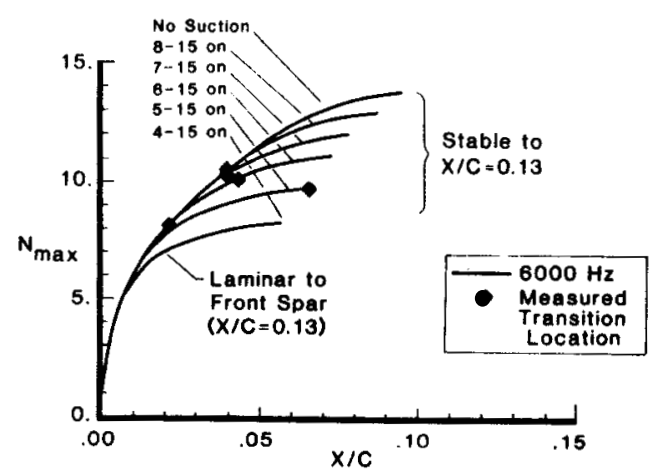

Figure 9. Effect of later suction on laminar boundary layer stability at $M=0.775$, $29000 \mathrm{ft}$. including curvature effects.

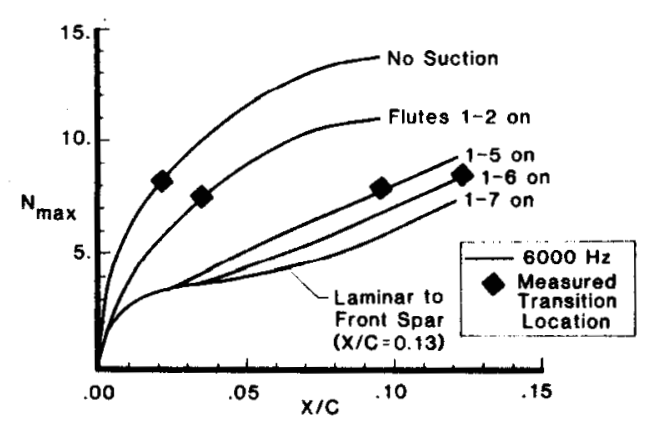

Figure 10. Effect of early suction on laminar boundary layer stability at $M=0.775$, $29000 \mathrm{ft}$. including curvature effects.

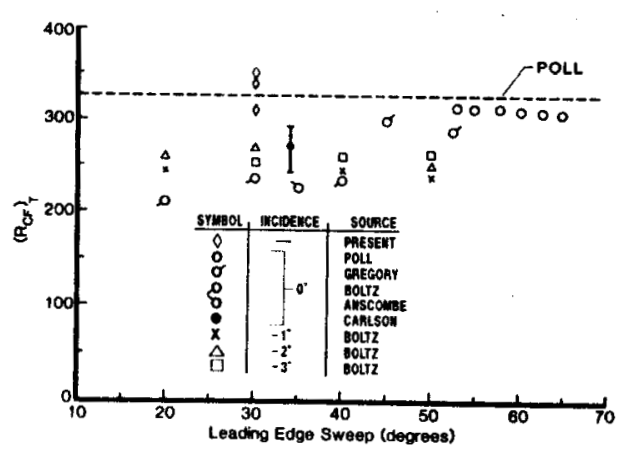

Figure 11. Crossflow Reynolds number for transition versus leading-edge sweep angle. 
